\title{
Eosinophilic fasciitis (Shulman's disease): review and comparative evaluation of seven patients
}

\author{
Joana Urzal ${ }^{1}$, Miriam Cimbron², Teresa Mendonça ${ }^{3}$, Fátima Farinha ${ }^{3}$ \\ ${ }^{1}$ Department of Internal Medicine, Hospital Professor Doutor Fernando Fonseca, Portugal \\ 2Department of Internal Medicine, Hospital do Divino Espírito Santo, Ponta Delgada, Portugal \\ ${ }^{3}$ Medicine Department, University Hospital Center of Porto, Portugal
}

\begin{abstract}
Objectives: Eosinophilic fasciitis (EF) was described in 1974 by Shulman as a rare fibrosing connective tissue disease of unknown etiology. An undetermined trigger is thought to lead to the degranulation of eosinophils that interact with fibroblasts and express fibrogenic cytokines including the transforming factor of tumor growth $a$ and $b$ and interleukins 1 and 6 . The purpose of this study was to summarize seven cases of EF in a central hospital.

Material and methods: This was a retrospective and descriptive study of a population with EF of a central hospital. All patients diagnosed with EF in a hospital unit were admitted to the study between January 1, 2005, and April 30, 2018.

Results: A total of seven patients diagnosed with EF were analyzed. The median age of the population at the time of diagnosis was 56 years, and $57 \%$ of the patients were women. All patients had elevated peripheral eosinophilia and sedimentation rate, and only one patient had hypergammaglobulinemia. All patients had edema and cutaneous thickening of the limbs, 57\% had constitutional symptoms, and $57 \%$ had inflammatory arthritis with joint contracture. Prednisolone (PDN) therapy was initiated in all patients, and only in two was the association of PDN with methotrexate (MTX) initially performed. In one patient triple therapy of PDN, MTX, and cyclosporine was required. At the time of this publication, only one patient maintains active disease, and tocilizumab has been initiated.

Conclusions: Recent studies show a more favorable response from the combination of PDN and MTX than from PDN alone. Considering the rarity of the disease, more long-term studies are needed regarding the etiopathogenetics, progression, recurrence of EF, and new effective therapies.

Key words: eosinophilic fasciitis, Shulman disease, groove sign, corticosteroids.
\end{abstract}

\section{Introduction}

In 1974 Shulman [1] described a rare scleroderma-like syndrome designated as eosinophilic fasciitis (EF). Eosinophilic fasciitis is rare disease characterized by subacute onset of erythema, edema, and induration of the skin and soft tissues of the limbs and trunk [2]. These manifestations are replaced by fascial fibrosis, leading to a cobblestone appearance or peau d'orange, as well as the "groove sign," a linear depression along the course of veins, accentuated by limb elevation, due to inward tethering of the skin. Concurrent plaque morphea can be present in $29-41 \%$ of cases. Extracutaneous involvement includes muscle pain and weakness [3], neuropathies such as carpal tunnel syndrome (23\%) [4], articular symptoms like joint contractures (50-56\%) [5], and arthritis (40\%) [6], with a high impact of morbidity related to EF. Visceral involvement is rare, but some cases have been reported as pericarditis [7], pleural effusions [8], and renal involvement.

Laboratory evaluation often reveals peripheral eosinophilia (58-85\%) [9], hypergammaglobulinemia (36-46\%) [7] monoclonal gammopathy (16\%) [8], and an elevated 
erythrocyte sedimentation rate (ESR), although it is not mandatory for the diagnosis.

The incidence of EF is uncertain. It occurs most commonly in middle-aged individuals, with peak incidence between 40 and 50 years of age.

The pathogenesis of EF is not well understood. Eosinophils degranulate and induce tissue damage, which results in fibrosis via accumulation of extracellular matrix. Various studies have indicated that eosinophils interact with fibroblasts and express fibrogenic cytokines including tumor growth factor (TGF) $\alpha$, TGF- $\beta$, interleukin (IL) 1 , and IL-6 [10].

There are some possible triggering factors or factors associated with EF, such as infections [11], initiation of hemodialysis [12], radiotherapy, graft-versus-host disease, hematological disorders, as well as autoimmune diseases [13] (primary biliary cirrhosis, systemic lupus erythematosus, Sjögren's syndrome). Other reasons for EF are also taken into account, such us: exposure to certain medications [14] (ramipril, phenytoin, subcutaneous heparin, statins), strenuous exercise, or trauma. However, most cases are considered as idiopathic. Rarely, EF can be associated with solid or hematological neoplasms [15]. Hematological abnormalities associated with EF include the following: multiple myeloma, lymphoma, myelodysplastic syndromes, myeloproliferative disorders, acquired amegakaryocytic thrombocytopenia, aplastic anemia, and paroxysmal nocturnal hemoglobinuria.

The diagnosis of EF is based on clinical features complemented by laboratory findings; however, universally accepted international diagnostic criteria are lacking. A full-thickness skin biopsy including the fascia usually confirms the diagnosis by demonstrating characteristic lymphocytic and eosinophilic infiltrate with thickened collagen bundles in the fascia. Magnetic resonance imaging (MRI) should be performed when the biopsy is non-diagnostic or cannot be obtained. Findings on MRI show an increased T2 signal in subcutaneous and deep fascia and enhancement of these structures on fat-suppressed T1 images after gadolinium administration. If MRI cannot be performed, 18-F-fluorodeoxyglucose positron emission tomography/computed tomography (FDG-PT/CT) [16] or ultrasound should be performed [17].

There are a variety of other disorders that should be considered in the differential diagnosis of EF. Systemic sclerosis (SSC) is the main differential diagnosis of EF. Sometimes EF can be misdiagnosed and there are some features that can help clinicians distinguish these two entities. In EF there is no skin tightening of distal digits, nailfold capillary changes, digital ulcers, or Raynaud's phenomenon. Histopathology in EF universally involves fascia and involvement of the dermis, subcutaneous fat, and muscle may occur, whereas in SSc only dermis and subcutaneous fat are involved [18].

Localized scleroderma includes morphea and linear scleroderma. These entities have a slowly progressive course and are not associated with significant eosinophilia.

In scleroderma-like disorders we can find skin thickening and decreased pliability. Scleromyxedema can occur alone or in association with malignancies. Scleroderma is associated with diabetes, plasma cell disorder, and monoclonal gammopathy. In the skin biopsy of scleroderma there is no evidence of inflammation.

Early treatment of patients with EF showed better outcomes in some studies, but these findings were not statically significant [19].

Currently, systemic corticosteroids (SCS) are the cornerstone of treatment. In those patients who develop a steroid-resistant disease the introduction of an immunosuppressive drug is essential. The most common agent used is methotrexate (MTX), especially in patients with morphea-like skin lesions. Other treatment options include hydroxychloroquine, azathioprine, cyclophosphamide, cyclosporine, or an anti-TNF agent (etanercept). There are some recent studies showing the efficacy of a therapy targeting IL-6 cytokine, tocilizumab (TCZ), in EF refractory to steroids and other immunosuppressive drugs [20].

\section{Material and methods}

This was an observational, retrospective, and descriptive study based on the population of Clinical Immunology Unit (CIU) in a single central hospital between January 1, 2005, and April 30, 2018.

\section{Population}

All adult patients diagnosed with EF followed in CIU. EF diagnosis was based on suggestive clinical, laboratory findings and with a biopsy-proven fascia involvement.

\section{Data collection}

We collected demographic and clinical data registered on the clinical software (SClinico $\left.{ }^{\circledR}\right)$ of all patients. Age and gender were used as demographic variables.

Clinical variables included evolution time of disease, anatomic localization of disease, and personal and familiar medical history. Other considered variables related to extracutaneous involvement were constitutional symptoms, history of edema, inflammatory arthritis, morning stiffness, hyperpigmented lesions, Raynaud syndrome, dysphagia or gastroesophageal reflux disease, and carpal tunnel syndrome.

The laboratory variables considered were peripheral eosinophilia, gammaglobulinemia, complement, antinuclear antibodies, and erythrocyte sedimentation rate. 
Series of EF are rarely published. The purpose of this study was to summarize seven cases, showing the clinical findings, laboratory results, histological characteristics, and immunosuppressive treatment used.

\section{Results}

\section{Study sample}

A total of seven patients were followed in CIU between January 2005 and April 2018. Mean age at diagnosis was $56 \pm 21.1$ years, and four patients were women. At the time of the study, patients had an average of 11 (1-41) years of disease progression.

Table I shows patients' characteristics such as anatomic localization of EF, and signs and symptoms and laboratory findings.

Regarding the anatomic localization, arms, forearms, and thighs were the most affected. Only one patient had familiar and personal history of autoimmune disease.
The immunological laboratory results such as antinuclear antibodies (ANA) and antineutrophil cytoplasmic antibodies (ANCA) were negative. Thyroid function (TSH, ft4, and $\mathrm{ft} 3$ ), thyroid peroxidase antibody (TPO), thyroglobulin antibody (TGAb), and thyroid stimulating hormone receptor antibody (TSHRAb) were negative.

In laboratory findings, all patients had peripheral eosinophilia and elevated ESR, and only one patient had hypergammaglobulinemia. None of the patients presented abnormalities in complement component levels. All patients had history of edema and skin induration. Constitutional symptoms and inflammatory arthritis with joint contracture were present in $57 \%$ of patients. Raynaud phenomenon and visceral involvement were not present in the described patients.

Nailfold capillaroscopy was performed in three patients, two of them were normal picture of naifoild capillaires and one showed nonspecific alterations. A full thickness incisional skin biopsy was performed in all pa-

Table I. Patients' characteristics

\begin{tabular}{|c|c|c|c|c|c|c|c|}
\hline Feature & Patient 1 & Patient 2 & Patient 3 & Patient 4 & Patient 5 & Patient 6 & Patient 7 \\
\hline Diagnosis age (years) & 5 & 60 & 28 & 56 & 36 & 56 & 61 \\
\hline Current age (years) & 19 & 67 & 69 & 63 & 42 & 58 & 62 \\
\hline Gender & Female & Female & Female & Male & Male & Male & Female \\
\hline \multicolumn{8}{|l|}{ Anatomic localization } \\
\hline Face & - & - & + & - & - & - & - \\
\hline Trunk & - & + & - & - & - & - & + \\
\hline Arms & - & - & + & + & + & + & + \\
\hline Forearm & - & - & - & + & + & + & + \\
\hline Hands & + & - & + & - & - & - & - \\
\hline Abdomen & - & + & - & + & - & - & + \\
\hline Thighs & - & - & + & + & + & - & + \\
\hline Ankle & + & - & - & - & - & - & - \\
\hline $\begin{array}{l}\text { Familiar history autoimmune } \\
\text { disease }\end{array}$ & + & - & - & - & - & - & - \\
\hline $\begin{array}{l}\text { Personal history autoimmune } \\
\text { disease }\end{array}$ & Vitiligo & - & - & - & - & - & - \\
\hline \multicolumn{8}{|l|}{ Laboratory findings } \\
\hline Eosinophilia & $10.4 \%$ & $8.3 \%$ & $9.2 \%$ & $10 \%$ & $9.1 \%$ & $9.2 \%$ & $10.3 \%$ \\
\hline Gammaglobulinemia & - & - & + & - & - & - & - \\
\hline Antinuclear antibodies & $1 / 160$ & $1 / 80$ & $1 / 80$ & $1 / 60$ & $1 / 80$ & $1 / 160$ & $1 / 80$ \\
\hline $\begin{array}{l}\text { Erythrocyte sedimentation rate } \\
(\mathrm{mm} / \mathrm{h})\end{array}$ & 80 & 60 & 65 & 60 & 54 & 65 & 68 \\
\hline \multicolumn{8}{|l|}{ Signs and symptoms } \\
\hline Constitutional symptoms & + & + & - & - & + & - & + \\
\hline Inflammatory arthritis & + & + & - & - & + & - & + \\
\hline Morning stiffness & - & + & - & - & + & - & + \\
\hline
\end{tabular}


tients, and histopathological assessment revealed infiltrated lymphocytes, plasma cells, histiocytes, and eosinophils. MRI was performed in one patient and showed thickening and global hypersignal of the forearm.

\section{Immunosuppressive treatment}

Table II shows the immunosuppressive treatment used in the treatment of analyzed patients. Prednisolone (PDN) was initiated in all patients with a $0.5-1 \mathrm{mg} / \mathrm{kg} /$ day initial dose. In this study, in only two patients was the combination of PDN with MTX initially performed (patients 4 and 7). The median time between disease onset and MTX initiation was three months, and the maximum dose was $20 \mathrm{mg} /$ week. One patient required triple therapy of PDN, MTX, and cyclosporine (initial dose $200 \mathrm{mg}$ ). Disease recurrence was observed only in one patient. Only one patient maintains active disease, and due the exuberant extension of fasciitis, subcutaneous tocilizumab 162 mg/week was initiated eight months after the disease onset. Six patients (86\%) achieved disease remission after a median time of 12 months (range, 3-24 months). No patient underwent psoralen and ultraviolet A therapy.

\section{Discussion}

Shulman's disease is rare, and high clinical suspicion is needed for the diagnosis, which can be difficult because of the differential diagnoses that should be considered.

Typical clinical manifestations include edema and skin thickening, with orange peel skin texture, and groove sign, with more common involvement in the extremities, neck, and trunk. Complaints of myalgias and muscle weakness are common. Inflammatory arthritis is only present in a minority of patients. In these patients, sclerodactyly and Raynaud's syndrome are absent, as well as visceral involvement, and hence they are compatible with this study [21].

Rarely, some conditions can accompany the disease like compartment syndrome [22], esophageal dysmotility [23], reactive hepatitis [24], contractures in the joints due to edema [25], and peripheral polyneuropathy [26]. Contractures in the joints were found in $57 \%$ of patients, which can be very disabling and drastically reduce the quality of life.

Frequent analytical findings include peripheral eosinophilia, which may be transient, increased ESR, and polyclonal hypergammaglobulinemia. The laboratory abnormalities can be transitory and are not mandatory for the diagnosis. In this study, peripheral eosinophilia was present in all patients.

In most cases, the diagnosis is confirmed by skin biopsy (thickening of the fascia with accumulation of lymphocytes and macrophages with or without eosinophilic infiltrate) [18], and in this study the result of the biopsy was consistent with the suspected disease. Magnetic resonance imaging may be performed in atypical cases or if the biopsy does not confirm the diagnosis.

The differential diagnoses include neoplasia, infections, systemic sclerosis and other scleroderma subsets such as morphea, and epidemic fasciitis syndromes caused by toxic agents such as myalgia-eosinophilia syndrome and toxic oil syndrome [27]. Neoplasia should be suspected when corticosteroid therapy is refractory. In our study, none of the patients had an underlying disease diagnosed.

Table II. Immunosuppressive treatment

\begin{tabular}{|c|c|c|c|c|c|c|c|}
\hline Therapeutics & Patient 1 & Patient 2 & Patient 3 & Patient 4 & Patient 5 & Patient 6 & Patient 7 \\
\hline PDN initial dose (mg) & 20 & 40 & 30 & 20 & 60 & 80 & 60 \\
\hline PDN maximum dose $(\mathrm{mg})$ & 20 & 40 & 30 & 20 & 60 & 80 & 60 \\
\hline $\begin{array}{l}\text { Time for introduction } \\
\text { of another (months) }\end{array}$ & 14 & 3 & 1 & 0 & 1 & - & 0 \\
\hline MTX initial dose (mg)/week & 17,5 & 5 & 10 & 10 & 5 & - & 7.5 \\
\hline MTX maximal dose (mg)/week & 25 & 15 & 20 & 20 & 17.5 & - & 20 \\
\hline $\begin{array}{l}\text { Time for introduction } \\
\text { of another (months) }\end{array}$ & - & - & - & 3 & - & - & 8 \\
\hline Current therapeutics & $\begin{array}{l}\text { MTX } 12.5 \\
\text { mg/week }\end{array}$ & $\begin{array}{l}\text { PDN } 5 \text { mg } \\
+ \text { MTX } 15 \\
\text { mg/week }\end{array}$ & $\begin{array}{l}\text { MTX } 17.5 \\
\text { mg/week }\end{array}$ & $\begin{array}{l}\text { CCP } 100 \\
\text { mg/daily + } \\
\text { PDN } 5 \text { mg/ } \\
\text { daily }\end{array}$ & $\begin{array}{l}\text { MTX } 7.5 \\
\text { mg/week }\end{array}$ & PDN $5 \mathrm{mg}$ & $\begin{array}{c}\text { PDN } 20 \text { mg/ } \\
\text { daily + MTX } 20 \\
\text { mg/week + TCZ } \\
162 \text { mg/week }\end{array}$ \\
\hline Active disease & - & - & - & - & - & - & + \\
\hline Disease recurrence & - & - & + & - & - & - & - \\
\hline
\end{tabular}


The standard treatment is systemic corticosteroid therapy [28]. Recent studies show a more favorable response of the combination of PDN and MTX than of PDN alone [29].

Currently there are new therapies that can improve the outcome of these patients, and it is fundamenta to establish effective therapy as early as possible, to obtain a better prognosis. The introduction of a therapy targeting IL-6 cytokine in the case of EF refractory to steroids and other immunosuppressive drugs has been described [30]. In this study, TCZ at $162 \mathrm{mg}$ for three months showed softening of the skin with a significant reduction of skin hardness.

Limitations of our study include its retrospective design and small study size.

\section{Conclusions}

Eosinophilic fasciitis is a rare disease that may present a variable spectrum of clinical manifestations.

The variability of the age, presentation form, and laboratory changes make the EF challenging from the point of view of the possible differential diagnoses, as well as the therapeutic management.

Considering the rarity of the disease, more long-term studies are needed regarding the etiopathogenesis, progression, recurrence of EF, and new effective therapies.

The authors declare no conflict of interest.

\section{References}

1. Shulman LE. Diffuse fasciitis with hypergammaglobulinemia and eosinophilia: a new syndrome? (abstract). J Rheumatol 1974; 1 (Suppl 1): 46.

2. Doyle JA, Ginsburg WW. Eosinophilic fasciitis. Med Clin North Am 1989; 73: 1157-1166.

3. Nassonova VA, Ivanova MM, Akhnazarova VD, et al. Eosinophilic fasciitis. Review and report of six cases. Scand J Rheumatol 1979; 8: 225-233.

4. Jones HR Jr, Beetham WP Jr, Silverman ML, Margles SW. Eosinophilic fasciitis and the carpal tunnel syndrome. J Neurol Neurosurg Psychiatry 1986; 49: 324-327.

5. Huppke P, Wilken B, Brockmann K, et al. Eosinophilic fasciitis leading to painless contractures. Eur J Pediatr 2002; 161: 528530.

6. Varga J, Griffin R, Newman JH, Jimenez SA. Eosinophilic fasciitis is clinically distinguishable from the eosinophilia-myalgia syndrome and is not associated with L-tryptophan use. J Rheumatol 1991; 18: 259-263.

7. Rizzo S. Eosinophilic pleuropericarditis and fasciitis. A new case. Monaldi Arch Chest Dis 2002; 57: 311-313.

8. Killen JW, Swift GL, White RJ. Eosinophilic fasciitis with pulmonary and pleural involvement. Postgrad Med J 2000; 76: 36-37.
9. Varga J, Griffin R, Newman JH, Jimenez SA. Eosinophilic fasciitis is clinically distinguishable from the eosinophilia-myalgia syndrome and is not associated with L-tryptophan use. J Rheumatol 1991; 18: 259-263.

10. Gomes I, Mathur SK, Espenshade BM, et al. Eosinophil-fibroblast interactions induce fibroblast IL-6 secretion and extracellular matrix gene expression: implications in fibrogenesis. J Allergy Clin Immunol 2005; 116: 796-804.

11. Mosconi S, Streit M, Brönimann M, Braathen L. Eosinophilic fasciitis (Shulman syndrome). Dermatology 2002; 205: 204206.

12. Florell SR, Egan CA, Gregory MC, et al. Eosinophilic fasciitis occurring four weeks after the onset of dialysis in a renal failure patient. J Cutan Med Surg 2001; 5: 33-36.

13. Bachmeyer $C$, Monge $M$, Dhôte $R$, et al. Eosinophilic fasciitis following idiopathic thrombocytopenic purpura, autoimmune hemolytic anemia and Hashimoto's disease. Dermatology 1999; 199: 282.

14. Long H, Zhang G, Wang L, Lu Q. Eosinophilic Skin Diseases: A Comprehensive Review. Clin Rev Allergy Immunol 2016; 50: 189-213.

15. Pinal-Fernandez I, Selva-O'Callaghan A, Grau JM. Diagnosis and classification of eosinophilic fasciitis. Autoimmun Rev 2014; 13: 379-382.

16. Kim HJ, Lee SW, Kim GJ, Lee JH. Usefulness of FDG PET/CT in the diagnosis of eosinophilic fasciitis. Clin Nucl Med 2014; 39: 801-802.

17. Kissin EY, Garg A, Grayson PC, et al. Ultrasound assessment of subcutaneous compressibility: a potential adjunctive diagnostic tool in eosinophilic fasciitis. J Clin Rheumatol 2013; 19: 382-385.

18. Lee HS, Chang SJ, Kang MS, et al. A case of eosinophilic fasciitis presenting as pitting edema of the lower extremities. Allergy Asthma Immunol Res 2014; 6: 179-182.

19. Endo Y, Tamura A, Matsushima Y, et al. Eosinophilic fasciitis: report of two cases and a systematic review of the literature dealing with clinical variables that predict outcome. Clin Rheumatol 2007; 26: 1445-1451.

20. Elhai M, Meunier M, Matucci-Cerinic M, et al. Outcomes of patients with systemic sclerosis-associated polyarthritis and myopathy treated with tocilizumab or abatacept: a EUSTAR observational study. Ann Rheum Dis 2013; 72: 1217-1220.

21. Haddad H, Sundaram S, Magro C, Gergis U. Eosinophilic fasciitis as a paraneoplastic syndrome, a case report and review of the literature. Hematol Oncol Stem Cell Ther 2014; 7: 90-92.

22. Niskanen L, Tulla H, Fräki J, Tahvanainen K. Compartment syndrome as a late complication of eosinophilic fasciitis. J Rheumatol 1989; 16: 1364-1365.

23. Behera B, Singh N, Chandrashekar L, et al. Eosinophilic fasciitis associated with Raynaud's phenomenon, esophageal dysmotility, positive antinuclear antibody and anti-neutrophil cytoplasmic antibody. Indian I Dermatol Venereol Leprol 2018; 84: 224-227.

24. Loeliger AE, van den Brink HR, Derksen RH, Bijlsma JW. Eosinophilic fasciitis presenting with a reactive hepatitis. Clin Rheumatol 1991; 10: 440-444.

25. Tsoi KL, Custers M, Bij de Vaate L, Jacobs JWG. Eosinophilic fasciitis. BMJ Case Rep 2012; 2012: bcr20126158. 
26. Bischoff L, Derk CT. Eosinophilic fasciitis: demographics, disease pattern and response to treatment: report of 12 cases and review of the literature. Int J Dermatol 2008; 47: 29-35.

27. Antic M, Lautenschlager S, Itin PH. Eosinophilic fasciitis 30 years after - what do we really know? Report of 11 patients and review of the literature. Dermatology 2006; 213: 93-101.

28. Lebeaux D, Francès C, Barete S, et al. Eosinophilic fasciitis (Shulman disease): new insights into the therapeutic management from a series of 34 patients. Rheumatology (Oxford) 2012; 51: 557-561.
29. Lakhanpal S, Ginsburg WW, Michet CJ, et al. Eosinophilic fasciitis: clinical spectrum and therapeutic response in 52 cases. Semin Arthritis Rheum 1988; 17: 221-231.

30. Espinoza F, Jorgensen C, Pers Y-M. Efficacy of Tocilizumab in the treatment of Eosinophilic fasciitis: Report of one case. Joint Bone Spine 2015; 82: 460-461. 